\title{
Project-based Robotics Courses for the Students of Mechanical Engineering Technology
}

\section{Dr. Zhou Zhang, New York City College of Technology}

Assistant Professor, Ph.D. Department of Mechanical Engineering Technology, CUNY New York City College of Technology, 186 Jay St, Brooklyn, NY 11201.

Email: Zhzhang@ citytech.cuny.edu

\section{Dr. Andy Zhang, New York City College of Technology}

Dr. Andy S. Zhang received his Ph.D. from the City University of New York in 1995. He is currently the program director of a mechatronics project in the New York City College of Technology/CUNY. For the past 15 years, Dr. Zhang has been working on bringing mechatronics technology to the undergraduate engineering technology curricula, on creating internship programs for the college students through collaboration with Brooklyn Navy Yard Development Corporation, and on helping high school students to learn mechatronics through various outreach activities such as FIRST Robotic Competition, Black Male Initiatives (BMI), Brooklyn Science Day, Google Geek Fair, and NYC Maker Faire. Dr. Zhang was responsible for creating four robotic concentration courses in 2016 for the mechanical engineering technology department at the college.

Dr. Mingshao Zhang, Southern Illinois University, Edwardsville

Mingshao Zhang is currently an Assistant Professor in Mechanical Engineering Department, Southern Illinois University Edwardsville. Before joining SIUE, he received Ph.D. and master degree in Mechanical Engineering from Stevens Institute of Technology and bachelor's degrees from University of Science and Technology of China. etc.

\section{Dr. Sven K. Esche, Stevens Institute of Technology (School of Engineering and Science)}

Sven Esche is a tenured Associate Professor at the Department of Mechanical Engineering at Stevens Institute of Technology. He received a Diploma in Applied Mechanics in 1989 from Chemnitz University of Technology, Germany, and was awarded M.S. and Ph.D. degrees from the Department of Mechanical Engineering at The Ohio State University in 1994 and 1997, respectively. He teaches both undergraduate and graduate courses related to mechanisms and machine dynamics, integrated product development, solid mechanics and plasticity theory, structural design and analysis, engineering analysis and finite element methods and has interests in remote laboratories, project-based learning and student learning assessment. His research is in the areas of remote sensing and control with applications to remote experimentation as well as modeling of microstructure changes in metal forming processes. He publishes regularly in peer-reviewed conference proceedings and scientific journals. At the 2006 ASEE Annual Conference and Exposition in Chicago, USA, he received the Best Paper Award for his article 'A Virtual Laboratory on Fluid Mechanics'. 
$126^{\text {th }}$ ASEE Annual Conference and Exposition

Tampa, Florida, USA, June 15 - 19, 2019

Zhang, Z., Zhang, A., Zhang, M., Esche, S. K.

\title{
Project-based Robotics Courses for the Students of Mechanical Engineering Technology
}

\author{
Zhou Zhang, Andy S. Zhang, Mingshao Zhang, Sven K. Esche
}

\begin{abstract}
Robotics program at many Colleges has continued to become more and more popular. However, the students of the robotics program of Mechanical Engineering Technology (MET) are facing three difficulties: (1) Weak fundamental knowledge related electrical engineering (EE), computer science (CS) and information technology (IT); (2) Difficulty in understanding the advanced concepts and theories of robotics; (3) Limited robotics class hours. Therefore, devising an efficient educational pedagogy for the robotics classes of the MET program is desirable.

In order to overcome the above-mentioned problems, a project-based pedagogy for the robotics program is devised and implemented in the Department of MET. There are three levels of robotics courses ranging from 'introduction', 'application' to 'advanced'. A series of projects corresponding to different levels are designed and then are assigned to students. The students learn and practice the fundamental theories of robotics through projects instead of mathematical analysis. This pedagogy has two advantages. First, the projects let the students understand the theories spontaneously and expand the given projects with these theories. Second, the goal of the proposed educational pedagogy is to release the dependency on advanced algorithms and optimization. Then, the students can familiarize themselves with the principal concepts of robotics, practice the application of hardware and software, create their own innovative projects and, prepare themselves for their entries into the job market, thus supporting the central educational goal of cultivating technologists in MET.
\end{abstract}

\section{Keywords: Robotics, Mechanical Engineering Technology, Frameworks}

\section{Introduction}

The fields of engineering and engineering technology have been broadened significantly by a number of emerging topics including additive manufacturing ${ }^{1}$, computer vision ${ }^{2}$, internet of things $(\mathrm{IoT})^{3}$, 3D reconstruction ${ }^{4}$, artificial intelligence $(\mathrm{AI})^{5}$, virtual reality (VR) ${ }^{6,7}$, etc. Currently, robotics is now integrating so many cutting-edge topics together to contribute to the world-wide innovations. Moreover, robotics has brought about a revolution at the Colleges. On one hand, the graduates of robotics gain great advantages over the traditional focuses in Mechanical Engineering (ME) or MET with respect to the employment opportunities and salaries ${ }^{8}$. Therefore, robotics is becoming one of the most attractive majors in the Department of ME and MET. On the other hand, robotics (as shown in Figure 1) is one of the most comprehensive majors since it needs to address many extremely complicated problems involving science, technology, engineering and math (STEM), for example, algebra, ME, EE, CS, and $\mathrm{IT}^{9}$. Hence, the students in robotics programs must master intensive interdisciplinary knowledge of STEM if they want to succeed in their chosen program. However, the students whose focus is robotics in MET are suffering three difficulties:

(1) The weak fundamental knowledge of EE, CS and IT is the main obstruction ${ }^{10}$. In MET, the baccalaureate-level courses mainly focus on the mechanical system design, mechanics, dynamics, 
and simulation ${ }^{11}$. In addition, in reference 11 , there are only two courses to introduce the mechatronics. Therefore, the students lack the systematical training in the area of EE, CS and IT. It means that the instructors must go over the relevant knowledge in order to let students catch up with the requirements of the robotics classes.

(2) One more challenge is to understand the advanced concepts and theories ${ }^{12}$. Technology programs mainly focus on hands-on skills instead of theoretical analysis ${ }^{13},{ }^{14}$. One of the educational goals in MET is to cultivate future technologists rather than researchers. The curricula of MET emphasize on the applications, but the curricula of ME emphasize the theories. This difference obviously impairs the students' deeper understanding of the advanced concepts and theories.

(3) The limited class hours constrain the extended applications and furtherly result in the lack of opportunities to practice the knowledge of advanced robotics ${ }^{15}$. In addition, the limited class hours also make it difficult to go over the fundamental knowledge of EE, CS and IT.

In order to overcome the above problems, it is necessary to devise an efficient educational pedagogy for the robotics program in the department of the MET.

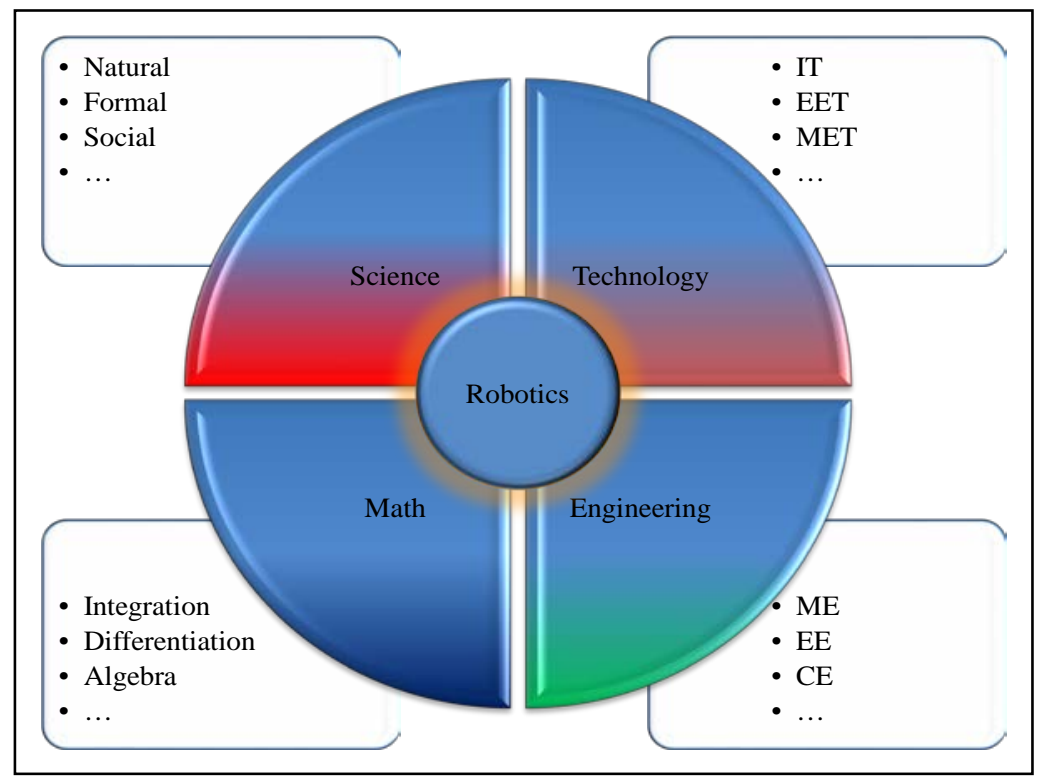

Figure 1: Knowledge structure of robotics

\section{Hierarchical Curricula of Robotics Program}

\subsection{Current robotics curricula design and its limitation for MET students}

In this paper, only the robotics curricula for the 4-year undergraduate students are discussed. robotics program is usually provided by EE, CS, or ME. Some institute takes robotics as an interdisciplinary engineering discipline ${ }^{16}$. Based on the commitments of the institutes and the students' qualities, the degree paths should be different. Generally, the fresh and sophomore are given the fundamental courses. For example, reference [17] introduced an implementation to migrate the components from the freshmen sequence into the sophomore engineering courses comprised of statics, circuits, and thermodynamics. Reference [18] used Lego Mindstorms kits to 
introduce the knowledge of robotics. Other implementations can be found in reference [19], reference [20], reference [21] and reference [22]. Although these implementations are efficient for their programs, they are not appropriate for the junior classes of robotics program in MET since the commercial robotics tools employed in these implementations prevent the students from practicing fundamental components. The senior-level robotics courses have been introduced in reference [23, 24, 25, 26, and 27]. In these kinds of literature, there are no exceptions to directly expose the students to the complicated control theories and algorithms. Certainly, this design method is reasonable for engineering students since they have more solid fundamental knowledge and stronger self-study ability. However, most of the students in the MET programs are struggling in the mathematics classes. At the same time, they usually need to support themselves, and cannot totally devote themselves to the class work. Therefore, how to utilize the limited class hours and how to integrate the knowledge into the practice become extremely critical for a successful pedagogy.

\subsection{Key components for successful educational pedagogy}

In order to introduce the novel model of pedagogy, it is important to figure out the key components for a successful educational pedagogy, and then to examine the implementations based on these components. It is well known that education is one form of training. The training is the process designed to help a person to acquire knowledge, skills, and competencies. Ten key components for success training include (i) collaboration, (ii) starting with the end in mind (backward design), (iii) awareness of learning styles, (iv) use of a variety of learning strategies, (v) awareness of audience / relevance, (vi) facilitation of learning vs. pure instruction, (vii) creation of authentic learning, (viii) active participation, (ix) use of assessment tools and (x) evaluation (see Figure 2) ) $^{28,29,30}$. The best educational pedagogy is to include all the components.

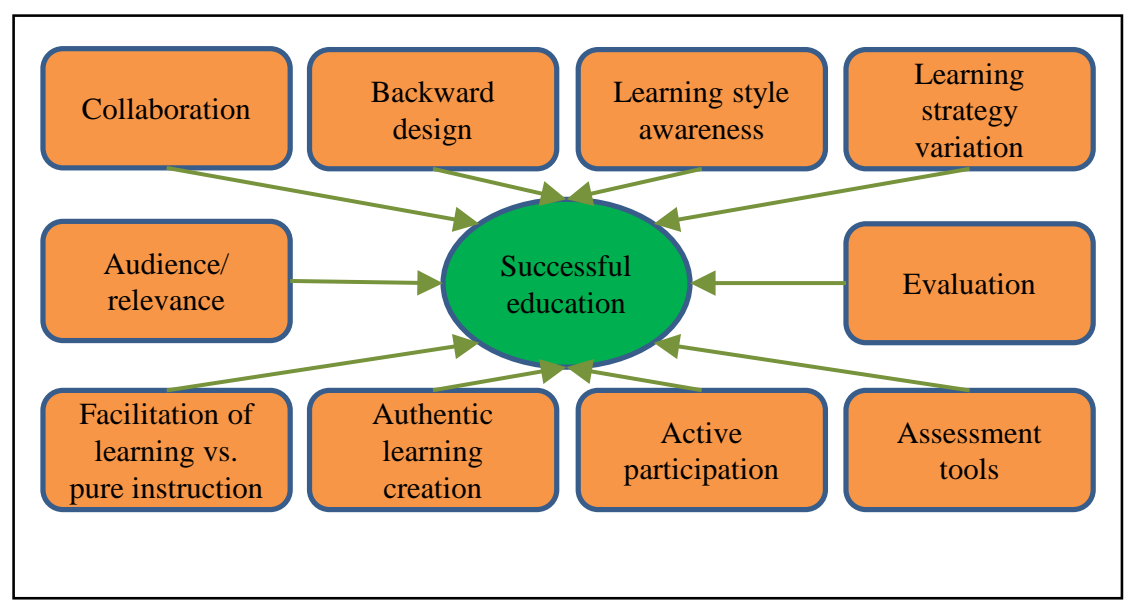

Figure 2: Ten key components for successful educational pedagogy

\subsection{Structure of hierarchical curricula}

The structure of the robotics curricula is gradual and hierarchical. The students must rise to the challenges of the more advanced courses while they keep progressing in their studies. Commonly, mastery of fundamental knowledge determines whether they can understand more sophisticated concepts. It is necessary for students to figure out how scientific theories are developed and what their limitations are, and then, to explore the potential applications of these theories ${ }^{31}$. Theoretically, the students who enrolled in the robotics classes are assumed having the 
fundamental knowledge as shown in Figure 1 and Table 1 when they finish the fourth semester ${ }^{32}$, 33, 34, 35, 36, 37, 38 . Following that, higher-level courses are given. By integrating the theories into the practice, the students can overcome the difficulties of the abstract theories, and develop their own applications.

Therefore, the ideal arrangement of different levels of robotics courses should be in a scaffolding form and range from 'introduction', 'application' to 'advanced'. The structure of hierarchical curricula can be found in Figure 3. The introduction level will go over the fundamental knowledge, typical applications, usage of basic components, and embedded programming. The application level will focus on the exploration of the potential applications of the knowledge introduced in the introduction level while the theories are expanded. The communication protocols and interfaces will be discussed in detail. Following these, the students should have the ability to integrate the theories into some advanced applications, for example, rescue robot, smart building, and robot arm. The advanced level will talk about the advanced control theories, advanced algorithms, and cognition in robotics. Therefore, the PID control, the algorithms of AI, and the knowledge of machine learning should be introduced and practiced. The anticipated outcomes of these courses will be that the students can solve the practice problems by themselves.

Table 1: Fundamental knowledge of STEM in the first two years

\begin{tabular}{|l|l|l|l|}
\hline Math: & Science: & Engineering: & Technology: \\
- Calculus & - Chemistry & - Materials & - Machining \\
- Differential & - Physics & - Mechanics & - Tooling \\
equations & • Liberal courses & - Dynamics & - Soldering \\
- Linear algebra & & - Drawing & - Programming \\
- Statistics & & - Circuits & - CAD \\
- Algorithm & & & \\
\hline
\end{tabular}

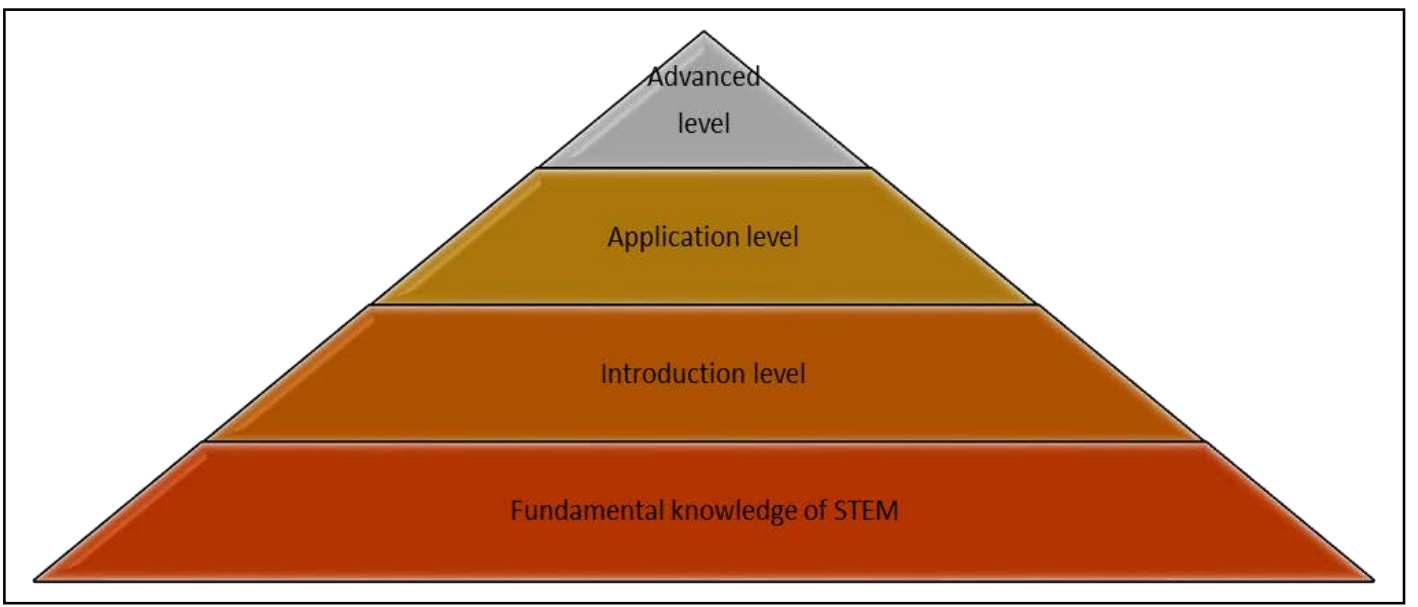

Figure 3: Structure of hierarchical curricula of robotics 


\section{Design of Robotics Curricula}

\subsection{Courses of introduction level}

The goal of the introductory course is to expose the students to robotics concepts, applications, and fundamental theories. Then, the students can deepen their understanding of the fundamental knowledge and familiarize themselves with the basic robotics techniques. Based on the key components of the successful education (refer to Figure 2), the qualifications of the students should be taken into account, and this aspect corresponds to the component of 'audience/relevance'. As discussed in the first part of this paper, the students of MET have three difficulties when they take the robotics courses. Therefore, the basic level was designed.

This course is "Introduction to Embedded Systems Fundamentals and Applications in Robotics" which lets students design a simple robotics system composed of mechanical transmission, chassis, power source unit (PSU), control module, and the communication module (refer to Figure 4). Through a series of design procedures, the students can master discipline-specific knowledge, skills, and tools. They can improve their capabilities with respect to the theoretical knowledge, the applications of hardware and software, the problem analysis, and the collaboration. In this course, the specific robotics system was a robot car called MazeBot. This was designed as a group project. The MazeBot was required to find out a path to escape from a maze. The project was decomposed into different parts based on Figure 4, and the final design was assumed to complete step by step with the proceeding of the course. This method was supported by several components of successful education: 'facilitation of learning', 'collaboration', 'learning style awareness', 'learning style variation', and 'active participation'.

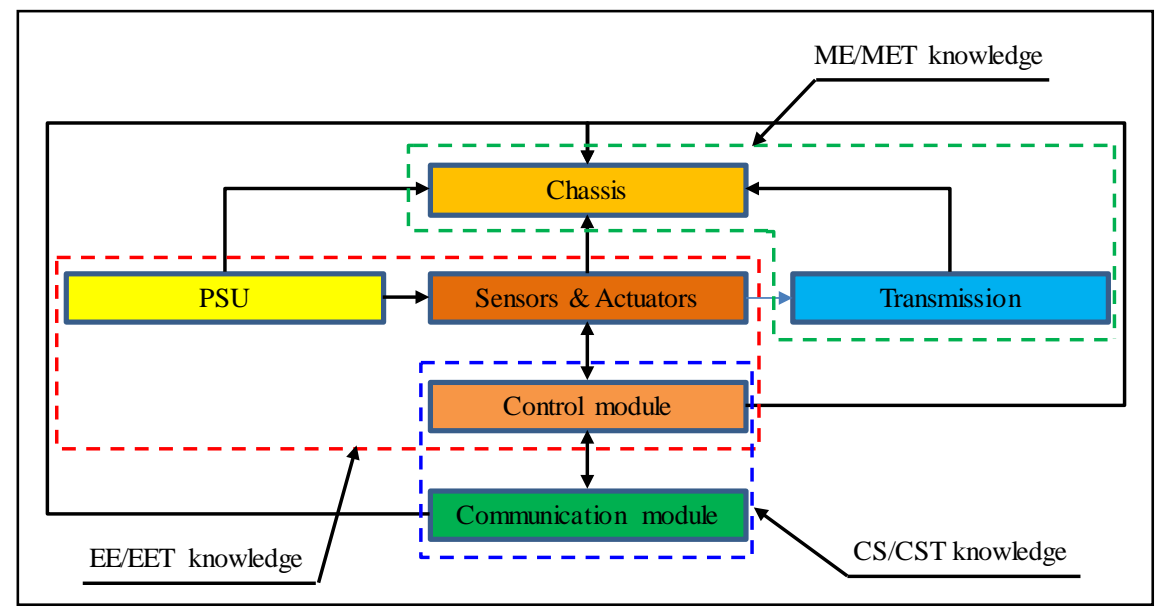

Figure 4: Structure chart of robotics system designed in class

At the beginning of this course, the embedded development kits (EDK) based on Arduino UNO R3 ${ }^{39}$ and the project of MazeBot were introduced. Then, the students were guided to go over and practice the fundamental knowledge of ME, EE, CS and IT through the EDK and the project. When the PSU was introduced, the analog circuit and corresponding components (resistor, capacitor, and inductor) were practiced in order to achieve a steady power source. When the EDK was employed, the fundamental knowledge of EE and CS were practiced which included the single-chip processor, peripheral circuit, serial communication, DA/AD converter, timer, logic, and embedded programming. For the part of sensors, only several simple sensors including thermosensor, IR sensor, and ultrasonic sensor were introduced in this course. For actuators, the 
relay, DC motor, and servo motor were introduced. The digital circuit and transistors were practiced during designing the control circuit of the motors. The Bluetooth-based wireless control was integrated into the MazeBot, and its function was to switch the power remotely via a smartphone ${ }^{40}$. All these works took 9 weeks. Although some new knowledge was discussed, the main goal of the above implementations was still to go over and apply the fundamental knowledge mastered in the first two years. Therefore, this process complied with the component of 'backward design'. Following that, the chassis and transmission system of MazeBot were designed. In this part, the knowledge of machine design, CAD, and mechanics was employed. It took 2 weeks since the students in MET had solid knowledge of $\mathrm{ME}^{41}$. Next, the students took 3 weeks to assemble the MazeBot, develop the algorithm to enable the MazeBot escaping from the maze, test the MazeBot, demonstrate their achievements, and present their projects. This 3-week time was a period of 'evaluation' and 'assessment'. Hitherto, all ten components of successful education had been included in this project-based course. One of the MazeBots designed by students can be found in Figure 5. This design employed the ultrasonic sensor, servo motor, DC motor, Bluetooth module, motor controller, Arduino EDK, the knowledge of CAD, programming, circuit design, algorithm design, and wireless communication. In addition, the appearance of Mecha Sonic demonstrated the students' imagination and the solid fundamental knowledge of industrial design.

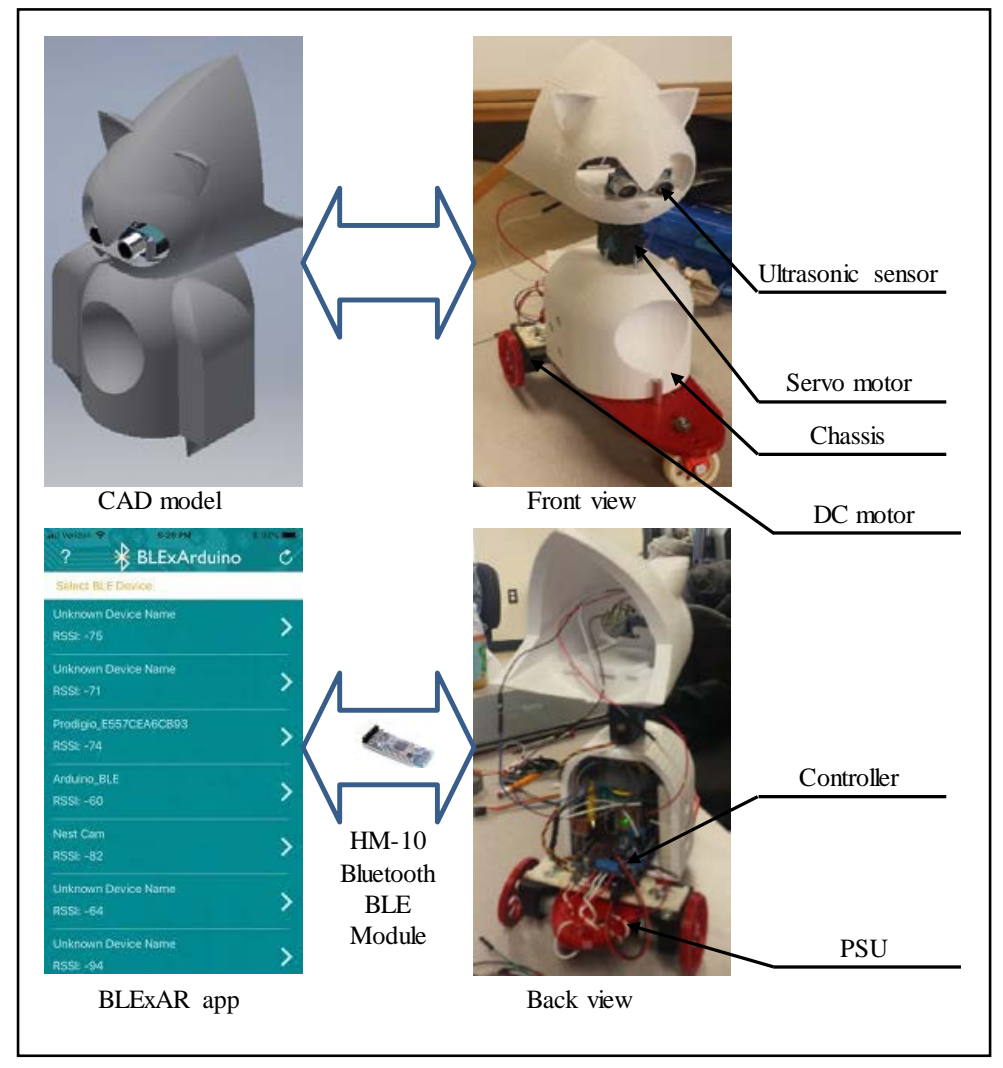

Figure 5: MazeBot with the appearance of Mecha Sonic

\subsection{Courses of application level}

In this level, the goal is to let students master the applications of popular sensors and actuators, practice various communication methods based on different protocols ${ }^{42}$, and combine the fundamental knowledge, skills and simple projects into complicated projects. One course named "Actuators and Sensors Application in Robotics" is designed to meet the objectives in this level. In 
this course, an educational framework of wireless sensor and control network was employed. The Arduino MEGA 2560 board, sensor and actuator kit was selected to implement the hands-on experiments. The students were assigned to different projects. Finally, one large project named 'smart building' synthesized some of these projects. This large project fully employed the educational framework to realize remote access and control to the appliances of the building. More details about this course can be found in [41]. The final project can be found in Figure $6^{41}$. In addition, the design of this course also obeys the rule: the ten components of successful education should be involved.

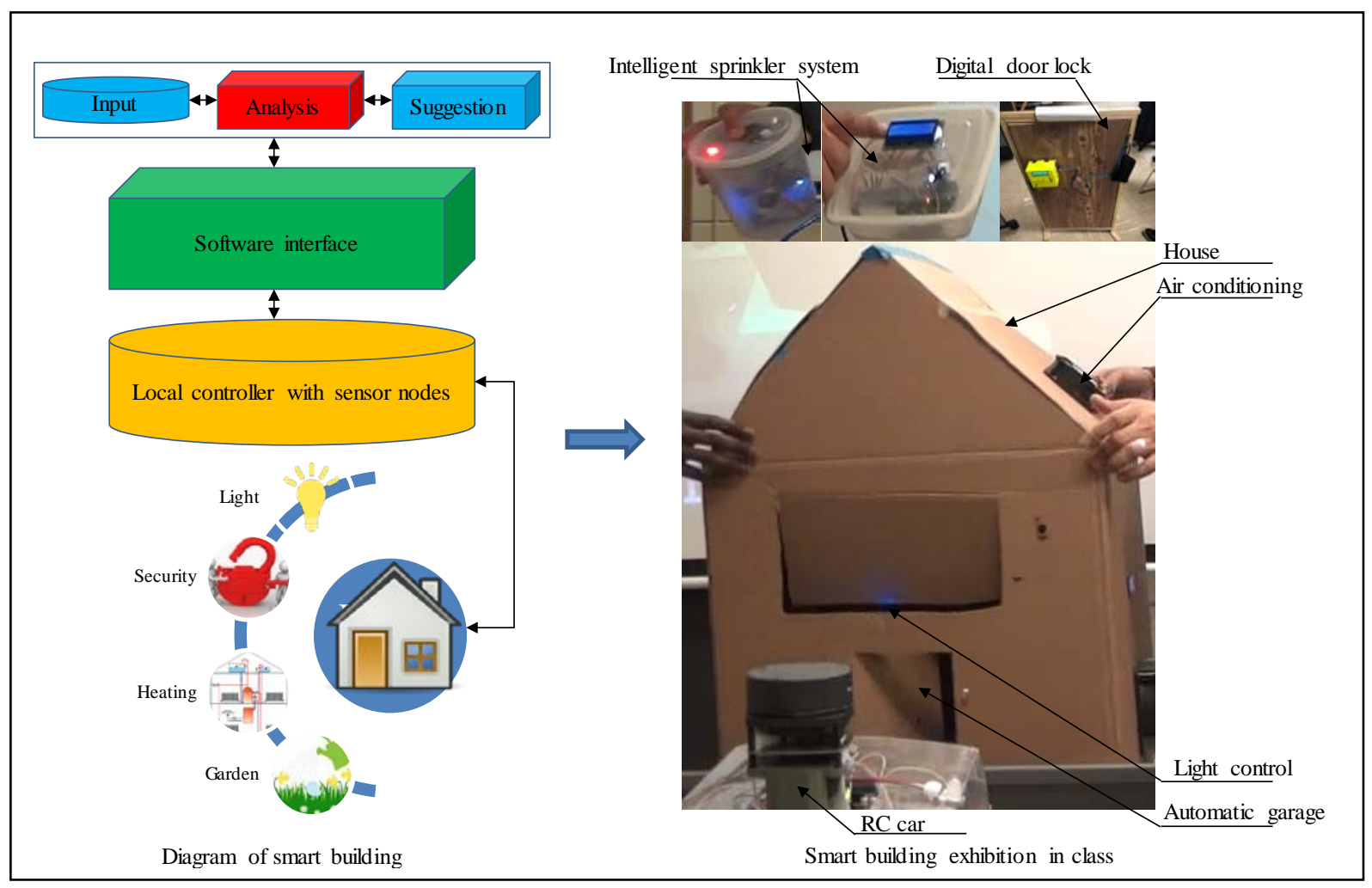

Figure 6: Project of smart building

\subsection{Courses of advanced level}

The courses of advanced level try to deliver and practice advanced knowledge involving hydraulic control, pneumatic control, PID control, and AI. There are two courses. One is "Control Systems in Robotics". The other is "Robotic Systems Design and Applications". The rule of the course design is the same as the former two levels. In the first course, the control techniques are emphasized. In the later one, the cutting-edge techniques of robotics are employed.

In the first course, the students were given the assignment of a project which must employ multiple control strategies and techniques involving hydraulic control, pneumatic control and PID control besides the skills gained through the courses of introduction level and application level. One of the projects named RescueBot in this course can be found in Figure 7. As an unmanned vehicle, RescueBot was designed to clear the obstruction on the road. It was equipped with a gyroscope, three ultrasonic sensors, pneumatic transmission system, and pneumatic breaker. The technique of path management was employed to realize self-driving in which the path was planned and 
optimized by dealing with a straight path, circle path, and the combination of the two types of paths ${ }^{43}$. The pneumatic breaker was used to destroy and clear the obstructions.

In the second course, AI is introduced and combined with the skills from the other three courses. One of the applications of AI used here was object recognition based on vision and machine learning. During this course, the students were guided to study the basic concepts involving data training, data classification, decision tree, and search algorithm. Following that, they were instructed to use the machine learning module and object recognition module in OpenCV to develop their own applications. One of the projects was SocialBot which had the abilities of face recognition and speech recognition (refer to Figure 8). SocialBot was composed of two Raspberry Pi boards to process and manage the data, two 'OpenMV Cam M7' cameras to acquire image information, one 'ReSpeaker Mic Array' mic array to realize speech recognition and one servo motor to rotate the head. For the details of the face recognition can be found in [44]. The method of speech recognition with 'ReSpeaker Mic Array' can be found in [45]. Since the limitation of the course hours, the mobility of the SocialBot was taken away, but the students enjoyed their achievement brought by the cutting-edge techniques.

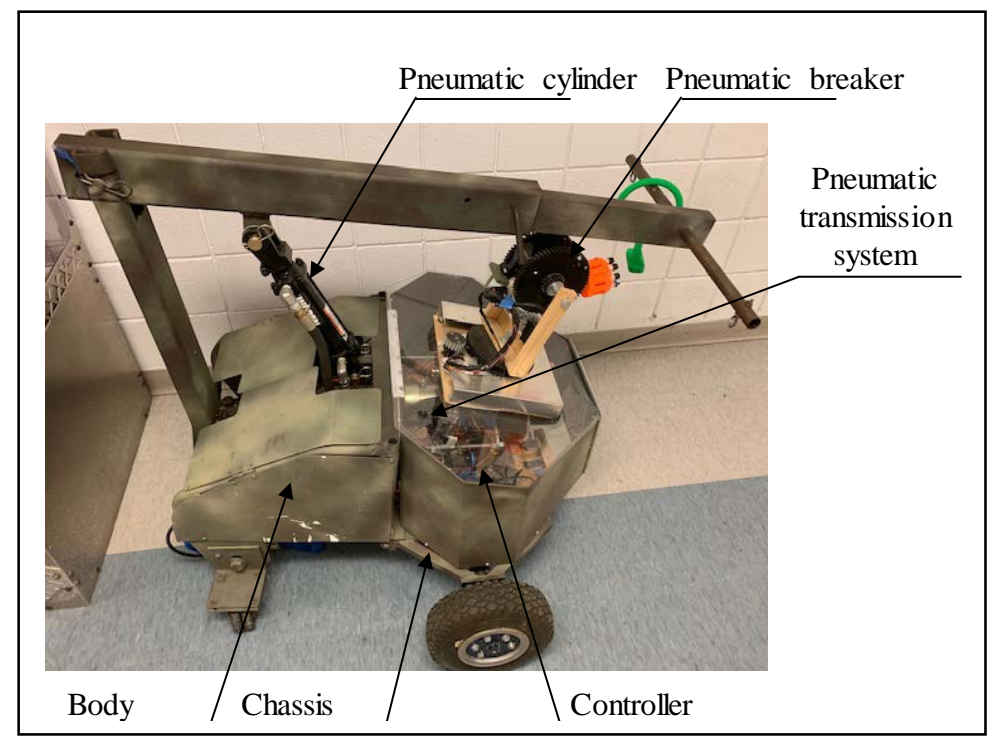

Figure 7: RescueBot

\section{Operation, Outcomes and Discussion}

The robotics program has been operated for 5 years, but it is still a new concentration compared with other concentrations in the department. Hitherto, one round has been implemented. Only the students of MET are enrolled in this series of classes. In the first level, there are about 20 students including sophomore and junior each semester. During the implementation, most of the students are willing to continue the robotics classes. Therefore, in the second level, there are about 18 students each semester. For the advanced level of classes, they are given in different semesters to guarantee the number of students in each class (about 17 students per class). In addition, any student who has taken either course of the first level and second level are qualified to enroll in the advanced classes. All the courses are administrated by the instructors who take the responsibility of preparing the experiments. Moreover, a peer assessment mechanism is established to evaluate the performance of the students. This mechanism combines the instructors' evaluation (70\%) and the evaluation from other students in the class (30\%) to decide the final individual grade. 
Certainly, the important evaluation standards of pedagogy are (1) the improvements in respect to the knowledge and the skills, (2) the students' career prospects. For the first standard, the in-class projects have shown that the students can master and apply the interdisciplinary knowledge, can solve the practical problems, can explore the potential applications of the fundamental theories, can employ modern design tools, and can demonstrate the creativity. In the project-based courses, the students gradually increase their capabilities following the scaffolding structure of the courses. The final scores after completing the projects ranged from 82 to 96. An assessment survey is administered at the conclusion of each course. The questions of the survey and average scores (on a scale of 1 to 5) of the answers are listed in Table 2. For the second standard, statistics about the internship and the fulltime positions received by the students of the robotics program of MET is made. The results of the statistics show that $78 \%$ of the junior students can get offers of internship of robotics, and $87 \%$ of the graduates can find full-time jobs related to robotics once graduating. These results are much better than other traditional concentrations of ME/MET (67\% and 71\% separately). Therefore, both the students' performance and their career prospects prove that the pedagogy is helpful to operate the robotics program in the department of MET.

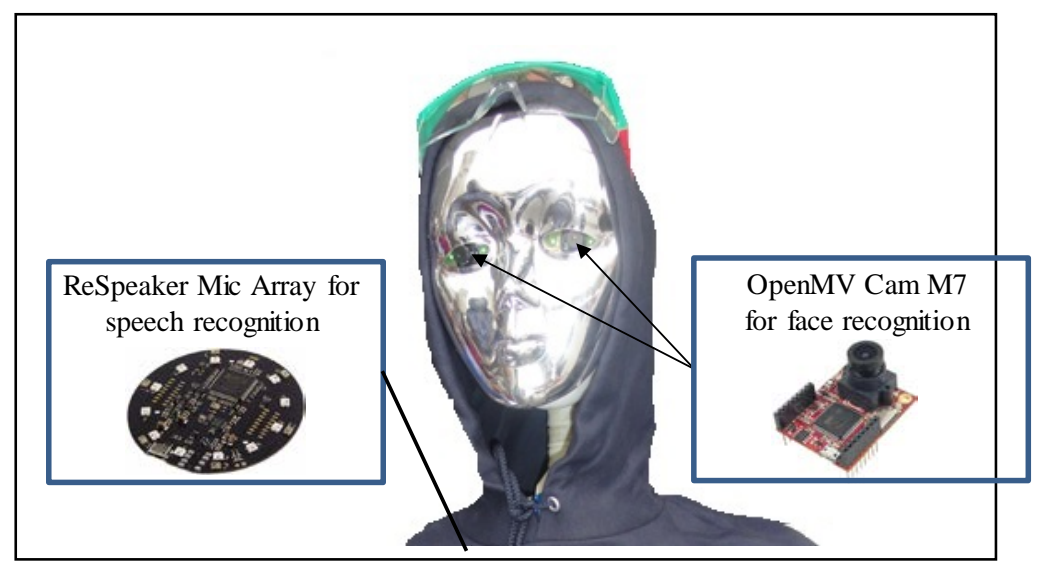

Figure 8: SocialBot

Table 2: Post-class survey results

\begin{tabular}{|l|l|}
\hline Questions: & Average score: \\
\hline Overall satisfaction (0 (No) to 5 (Yes)) & 4.6 \\
\hline Obtain practical skills for a future career (0 (No) to 5 (Yes)) & 4.8 \\
\hline Learn more through projects than lecture-style courses (0 (No) to 5 (Yes)) & 4.5 \\
\hline Hands-on project is helpful to understand theories (0 (No) to 5 (Yes)) & 4.6 \\
\hline Master embedded system development skills (0 (No) to 5 (Yes)) & 4.3 \\
\hline Professional in programming (0 (No) to 5 (Yes)) & 3.9 \\
\hline Professional in circuit design (0 (No) to 5 (Yes)) & 4.0 \\
\hline Projects are difficult (0 (No) to 5 (Yes)) & 3.8 \\
\hline Projects are interesting (0 (No) to 5 (Yes)) & 4.8 \\
\hline Recommendation Robotic courses to others (0 (No) to 5 (Yes)) & 4.9 \\
\hline
\end{tabular}


$126^{\text {th }}$ ASEE Annual Conference and Exposition

Tampa, Florida, USA, June 15 - 19, 2019

Zhang, Z., Zhang, A., Zhang, M., Esche, S. K.

\section{Conclusions and Future Work}

In this paper, the design of curricula for the robotics program of MET is introduced. This work is the most critical part of a hands-on-project-based pedagogy. In order to explain why the new pedagogy is necessary, the difficulties faced by students of the robotics program of MET are discussed. Then, the hierarchical curricula in robotics program are presented after a series of discussions including a survey of the robotics curricula, an introduction of the component of successful education, and the structure of hierarchical curricula. Following that, the scaffolding structure curricula are designed, which include introduction level, application level, and advanced level. The introduction level is to combine the fundamental STEM knowledge together to enable students solving practical problems. The application level is to guide the students to expand the application of the theories. The advanced level is to facilitate the students to integrate the cutting-edge techniques into practical applications. It has been proved that the new pedagogy can enhance the students' understanding of the fundamental concepts, can inspire the students' interest in robotics, and can improve the students' performance. In the future, the robotics curricula will be optimized further to adapt to the development of society. In addition, more up-to-date techniques will be introduced and applied in class projects.

\section{Acknowledgments}

The authors wish to thank the students of the robotics program in the Department of Mechanical Engineering Technology at the CUNY New York City College of Technology.

\section{References}

[1] Türk, D.A., Triebe, L. \& Meboldt, M., 2016, “Combining additive manufacturing with advanced composites for highly integrated robotic structures”, Procedia CIRP, Vol. 50, pp 402-407.

[2] Zhang, Z., Zhang, M., Chang, Y., Esche, S. K. \& Chassapis, C., 2016, “A virtual laboratory system with biometric authentication and remote proctoring based on facial recognition”, Computers in Education Journal, Vol. 7, No. 4, pp. 74-84.

[3] Hamblen, J.O. \& Van Bekkum, G.M., 2013, “An embedded systems laboratory to support rapid prototyping of robotics and the internet of things”, IEEE Transaction of Education, Vo. 56, No. 1, pp. 121-128.

[4] Zhang, Z., Zhang, M., Chang, Y., Esche, S. K. \& Chassapis, C., 2016, "Real-time 3D reconstruction for facilitating the development of game-based virtual laboratories”, Computers in Education Journal, Vol. 7, No. 1, pp. 85-99.

[5] Brady, M., 1984, “Artificial intelligence and robotics”, In Robotics and Artificial Intelligence, pp. 47-63, Springer, Berlin, Heidelberg.

[6] Zhang, Z., Zhang, M., Chang, Y., Aziz, E.-S., Esche, S. K. \& Chassapis, C., 2018, “Collaborative virtual laboratory environments with hardware in the loop”, In Cyber-Physical Laboratories in Engineering and Science Education, Springer, pp. 363-401.

[7] Zhang, M., Zhang, Z., Chang, Y., Aziz, E.S., Esche, S. \& Chassapis, C., 2018, "Recent developments in game-based virtual reality educational laboratories using the Microsoft Kinect”, International Journal of Emerging Technologies in Learning (iJET), Vol. 13, No. 1, pp. 138-159.

[8] Wisskirchen, G., Biacabe, B.T., Bormann, U., Muntz, A., Niehaus, G., Soler, G.J. \& von Brauchitsch, B., 2017, “Artificial intelligence and robotics and their impact on the workplace”, IBA Global Employment Institute. 
$126^{\text {th }}$ ASEE Annual Conference and Exposition

Tampa, Florida, USA, June 15 - 19, 2019

Zhang, Z., Zhang, A., Zhang, M., Esche, S. K.

[9] Yang, G.Z., Bellingham, J., Dupont, P.E., Fischer, P., Floridi, L., Full, R., Jacobstein, N., Kumar, V., McNutt, M., Merrifield, R. \& Nelson, B.J., 2018, “The grand challenges of science robotics”, Science Robotics, Vol. 3, No. 14, pp. eaar7650-7664.

[10] Stern, F., Xing, T., Muste, M., Yarbrough, D., Rothmayer, A., Rajagopalan, G., Caughey, D., Bhaskaran, R., Smith, S. \& Hutchings, B., 2003, Integration of simulation Technology into undergraduate engineering courses and laboratories”, Proceedings of ASEE 2003 Annual Conference, Nashville, Tennessee, USA, June 22-25, 2003.

[11] Jovanovic, V., Verma, A. \& Tomovic, M.M., 2013, "Development of courses in mechatronics and mechatronic system design within the mechanical engineering technology program", Proceedings of the 11th Latin American and Caribbean Conference for Engineering and Technology, 14 - 16 August, 2013, Boca Raton, Florida, USA.

[12] Jovanovic, V.M., Michaeli, J.G., Popescu, O., Moustafa, M.R., Tomovic, M., Verma, A.K. \& Lin, C.Y., 2014, "Implementing mechatronics design methodology in mechanical engineering technology senior design projects at the Old Dominion University, Proceeding of 121st ASEE Annual Conference \& Exposition, Indianapolis, Indiana, USA, June 15-18, 2014.

[13] Gqibani, S., Clarke, N. \& Nel, A.L., 2018, "The order of skills development for technician and technologist training curricula”, Proceedings of 2018 IEEE Global Engineering Education Conference, Santa Cruz de Tenerife, Canary Islands, Spain, April 18-20, 2018.

[14] Zhang, Z., Zhang, A.S., Zhang, M. and Esche, S.K., 2019, "Design and application of a platform of wireless sensor and control network in robotics course of mechanical engineering technology", Computers in Education Journal, Vol. 10, No. 1, pp. $1-7$.

[15] Cheng, H., Hao, L., Luo, Z. \& Wang, F., 2016, "Establishing the connection between control theory education and application: an Arduino based rapid control prototyping approach, International Journal of Learning and Teaching, Vol. 2, No. 1, pp. 67-72.

[16] Gennert, M.A. \& Putnam, C.B., 2018, "Robotics as an Undergraduate Major: 10 Years' Experience”, Proceedings of 125th ASEE Annual Conference \& Exposition, Salt Lake City, UT, USA, June 24-27, 2018.

[17] Harbour, D. \& Hummel, P., 2010, "Migration of a robotics platform from a freshman introduction to engineering course sequence to a sophomore circuits course, Proceedings of Frontiers in Education Conference, Arlington, Virginia, USA, 27 - 30 October 2010.

[18] Tester, J.T., 2008, "Management of a large team-design and robotics-oriented sophomore design class", Proceedings of 38th ASEE/IEEE Frontiers in Education Conference, October 22 - 25, 2008, Saratoga Springs, NY, USA.

[19] Azemi, A. \& Esparragoza, I., 2005, "Problem-based collaborative projects in and between freshman and sophomore engineering courses", Proceedings of ASME 2005 International Mechanical Engineering Congress and Exposition, Orlando, Florida, USA, November 5 - 11, 2005.

[20] Zhang, M., Zhang, Z., Lotfi, N. \& Esche, S. K., 2017, "Development of automatic reconfigurable robotic arms using vision-based control”, Proceedings of the 2017 ASEE Annual Conference \& Exposition, Columbus, Ohio, USA, June 25-28, 2017.

[21] Zhang, M., Duan, P., Zhang, Z. and Esche, S.K., 2018, "Development of telepresence teaching robots with social capabilities”, Proceeding of ASME International Mechanical Engineering Conference \& Exposition IMECE'18, Pittsburgh, PA, USA. November 9-15, 2018.

[22] Momeni, A., Previlon, F., Despopoulos, A., Schirner, G., Kimani, J. \& Kaeli, D., 2015, “Engaging sophomores in embedded design using robotics", Proceedings of the Workshop on Computer Architecture Education, Portland, OR, USA, June 13, 2015.

[23] Mataric, M.J., 2004, "Robotics education for all ages”, Proceedings of AAAI Spring Symposium on Accessible, Hands-on AI and Robotics Education, Stanford University, Palo Alto, California, USA, March 22-24, 2004. 
$126^{\text {th }}$ ASEE Annual Conference and Exposition

Tampa, Florida, USA, June 15 - 19, 2019

Zhang, Z., Zhang, A., Zhang, M., Esche, S. K.

[24] Correll, N., Wing, R. \& Coleman, D., 2013, “A one-year introductory robotics curriculum for computer science upperclassmen”, IEEE Transactions on Education, Vol. 56, No. 1, pp. 54 - 60.

[25] Cappelleri, D.J. \& Vitoroulis, N., 2013, “The robotic decathlon: Project-based learning labs and curriculum design for an introductory robotics course”, IEEE Transactions on Education, Vo. 56, No. 1, pp. 73 - 81.

[26] Ciaraldi, M., Cobb, E., Looft, F., Norton, R. \& Padir, T., 2009, “Designing an undergraduate robotics engineering curriculum: Unified robotics I and II”, Proceedings of the 2009 ASEE Annual Conference \& Exposition, Austin, Texas, USA, June 14 - 17, 2009.

[27] Padir, T., Gennert, M.A., Fischer, G., Michalson, W.R. \& Cobb, E.C., 2010, "Implementation of an undergraduate robotics engineering curriculum”, Computers in Education Journal, Vo. 1, No. 3, pp. 92-101.

[28] http://www.pages.drexel.edu/ ctc27/tenkey.html, accessed in January, 2019.

[29] Chang, Y., Aziz, E.-S., Zhang, Z., Zhang, M. \& Esche, S. K., 2016, "Usability evaluation of a virtual educational laboratory platform”, Computers in Education Journal, Vol. 7, No. 1, pp. 24-36.

[30] Chang, Y., Aziz, E.-S., Zhang, Z., Zhang, M., Esche, S. K. \& Chassapis, C., 2014, “A platform for mechanical assembly education using the Microsoft Kinect”, Proceedings of the ASME International Mechanical Engineering Conference \& Exposition IMECE'14, Montreal, Quebec, Canada, November 14-20, 2014.

[31] Danielson, S., Hawks, V. \& Hartin, J.R., 2006, “Engineering technology education in an era of globalization”, Proceedings of the 36th Frontiers in Education Conference, San Diego, California, USA, October 28-31, 2006.

[32] Worcester Polytechnic Institute, “Undergraduate catalog 2018 - 2019”, Wpi.edu

[33] New York City College of Technology, “Catalog spring 2019”, Citytech.cuny.edu.

[34] University of California Santa Cruz, "Robotics engineering B.S. degree 2017-2018 curriculum chart”, Ucsc.edu.

[35] University of Michigan Dearborn, “Robotics engineering core curriculum 2018”, Umdearborn.edu.

[36] Lawrence Technological University, "Bachelor of science in robotics engineering (BSRE) flowchart, Fall 2017”, Ltu.edu.

[37] Central Conneticut State University, "Bachelor of science in robotics and mechatronics engineering technology program”, Ccsu.edu

[38] Purdue University, “2018 - 2019 University catalog: robotics engineering technology, BS”, Purdue.edu.

[39] Barrett, S.F., 2013, “Arduino microcontroller processing for everyone!”, Synthesis Lectures on Digital Circuits and Systems, Vol. 8, No. 4, pp. 1-513.

[40] https://engineersportal.com/blexar, accessed in January 2019.

[41] Zhang, Z., Zhang, A.S., Zhang, M. \& Esche, S.K., 2018, “Conceptual framework for integrating a wireless sensor and control network into a robotics course for senior students of mechanical engineering technology", Proceedings of the 2018 ASEE Annual Conference \& Exposition, Salt Lake City, UT, USA, June 24-27, 2018.

[42] Zhang, Z., Zhang, M., Tumkor, S., Chang, Y., Esche, S. K. \& Chassapis, C., 2013, "Integration of physical devices into game-based virtual reality”, International Journal of Online Engineering, Vol. 9, No. 5, pp. 25-38.

[43] Liu, Y. \& Bucknall, R., 2015, "Path planning algorithm for unmanned surface vehicle formations in a practical maritime environment”, Ocean Engineering, Vol. 97, pp. 126-144.

[44] Zhang, Z., Aziz, E.S., Esche, S. \& Chassapis, C., 2018, “A virtual proctor with biometric authentication for facilitating distance education”, In Online Engineering \& Internet of Things, pp. 110-124, Springer, Cham.

[45] http://wiki.seeedstudio.com/ReSpeaker_Mic_Array_v2.0/, Accessed in January 2019. 